\title{
THE NEXT-GENERATION CONSTITUTIVE CORRELATIONS FOR SIMULATION OF CYCLIC STRESS-STRAIN BEHAVIOUR OF SAND
}

\author{
Habib SHAHNAZARI ${ }^{\mathrm{a}}$, Yasser DEHNAVI ${ }^{\mathrm{b}}$, Amir H. ALAVI ${ }^{\mathrm{c}}$ \\ ${ }^{a}$ School of Civil Engineering, Iran University of Science and Technology, Tehran, Iran \\ ${ }^{b}$ Department of Civil Engineering, University of Bojnord, Bojnord, Iran \\ ${ }^{c}$ Department of Civil and Environmental Engineering, Michigan State University, \\ East Lansing, MI, 48824, USA
}

Received 15 May 2012; accepted 10 Jul 2012

\begin{abstract}
This paper presents an innovate approach to simulate the stress-strain behaviour of sands subjected to large amplitude regular cyclic loading. New prediction correlations were derived for damping ratio $(D)$ and shear modulus $(G)$ of sand utilizing linear genetic programming (LGP) methodology. The correlations were developed using several cyclic torsional simple shear test results. In order to formulate $D$ and $G$, new equations were developed to simulate hysteresis strain-stress curves and maximum shear stress $\left(\tau_{\max }\right)$ at different loading cycles. A genetic algorithm analysis was performed to optimize the parameters of the proposed formulation for stress-strain relationship. A total of 746 records were extracted from the simple shear test results to develop the $\tau_{\max }$ predictive model. Sensitivity and parametric analyses were conducted to verify the results. To investigate the applicability of the models, they were employed to simulate the stress-strain curves of portions of test results that were not included in the analysis. The LGP method precisely characterizes the complex hysteresis behaviour of sandy soils resulting in a very good prediction performance. The proposed design equations may be used by designers as efficient tools to determine $D$ and $G$, specifically when laboratory testing is not possible.
\end{abstract}

Keywords: cyclic stress-strain relationship, linear genetic programming, damping ratio, shear modulus, hardening.

\section{Introduction and background}

An important concern to design engineering geosystems is to provide precise estimations of stress-strain response of soils under cycling loading. Shear modulus and damping ratio are key characteristics of strain-stress curves (hysteresis loops) of soils under cyclic loading (Zhang et al. 2005; Okura, Ansal 2007). These parameters denote the soil effective stiffness and dissipation of energy within the soil, respectively. The response of soils to cyclic loading is shown to be dependent on the range of applied shear strain (e.g. Ishihara 1996; Sagaseta et al. 1991). Accordingly, three major categories are considered for the models developed to predict stress-strain relationship of soil under cyclic loading (Ishihara 1996; Shahnazari et al. 2010):

(1) Elastic models are used for small range of shear strain. In this case, the shear modulus is a key parameter to model the stress-strain behaviour of soil.

(2) Visco-elastic models are used for medium range of shear strain (i.e. shear strain $<10^{-3}$ ). In this case, the soil behaviour becomes elasto-plastic and the shear modulus and damping ratio are functions of the shear strain. However, the shear modulus and damping ratio are independent from progression of cycles.
(3) Numerical procedures involving step-by-step integration techniques are employed to simulate the stress-strain response of soil in large range of shear strain (i.e. shear strain $>10^{-2}$ ). In this case, the shear modulus and damping ratio change with both the shear strain and the progression of cycles. Nearly all these methods couple a backbone curve (also called skeleton curve) with a series of constitutive laws. The stress-strain relationships can be specified at each step of loading, unloading and reloading phases (Ishihara 1996; Shahnazari et al. 2010). The stressstrain relationship of soil at large strain and under cyclic loading is affected by various parameters such as loading conditions, initial relative density, stress history, loading rate, and confining pressure (Ishihara 1996; Banimahd et al. 2005; Shahnazari et al. 2010). Based on several studies (Jennings 1964; Kondner 1963; Kulhawy, Duncan 1972; Tatsuoka et al. 2003), monotonic stress-strain relationship of geomaterials during original loading can be used as the skeleton curve. If the skeleton curve is known, the hysteresis loops can be constructed by applying Masing rule or extended Masing rule (Kramer

Corresponding author: Habib Shahnazari

E-mail:ah_alavi@hotmail.com; alavi@msu.edu 
1996). Thereafter, the damping ratio and shear modulus can be obtained from the constructed hysteresis loops. However, majority of these constitutive models need calibration parameters that should be obtained from at least one laboratory test. Furthermore, in most cases, these models do not directly incorporate the important effect of the progression of cycles and other loading conditions and physical properties (Shahnazari et al. 2010).

Investigations on the monotonic stress-strain relationship of soils have approached an advanced level.

Conversely, studies on the cyclic behaviour of soils are still limited (Ishihara 1996). This is because mathematical formulations of the cyclic behaviour are quite complex (Chen, Saleeb 1994). Several researchers have modelled the shear stress-strain response of geomaterials in cycling loading under both axial and triaxial loading environments (Bardet 1995). In general, the existing formulations are extensions of Masing rules (Pyke 1979; Thiers, Seed 1968) or they are on the basis of some constitutive laws (Bazant, Krizek 1976). Such models have limitations because it is not an easy task to incorporate all aspects of geomaterial behaviour in them.

Empirically modelling of the stress-strain behaviour using machine learning techniques is an alternative to the more difficult methods based on elasticity and plasticity theories (Shahnazari et al. 2010). Over the last decade, machine learning has attracted much attention in both academic and empirical fields for tackling civil engineering problems. The machine learning systems are powerful tools for design of computer programs. They automatically learn from experimental data and extract various discriminators (Mitchell 1997). Artificial neural networks (ANNs) are the most widely used branch of machine learning for solving problems in civil engineering problems (Hoła, Schabowicz 2005; Azmathulla et al. 2005, 2006; Malinowski et al. 2006; Kaplinski, Janusz 2006; Schabowicz, Hola 2007; Sonmez, Ontepeli 2009; Dikmen, Sonmez 2011). ANNs have been successfully used to model the cyclic behavior of geomaterials (Basheer 2000, 2002; Cabalar, Cevik 2009). Despite the acceptable performance of ANNs, they are not usually able to provide practical prediction equations. Furthermore, the structure of ANNs should be identified in advance. This is usually done through extensive trial studies (Alavi et al. 2011). To cope with this issue, more robust tools are required to formulate the cyclic stress-strain behaviour of soils.

Genetic algorithm (GA) is a well-known optimization tool which is based on the principles of genetics and natural selection. GA has been applied several engineering problems (Baušys, Pankrašovaite 2005; Šešok, Belevicius 2008; Šešok et al. 2010). The novel evolutionary computation, genetic programming (GP) (Koza 1992), is known as an extension of GA where the solutions are computer programs rather than fixed length binary strings (Koza 1992; Gandomi, Alavi 2011). GP can be considered as an alternative approach to ANNs and other conventional methods for dealing with civil engineering problems. The main advantage of GP is its ability to generate prediction equations without assuming prior form of the existing relationship (Alavi et al. 2011). Classical (standard) GP and its branches have been recently used to develop simplified formulations for civil engineering problems (Johari et al. 2006; Sun et al. 2009). Cevik and Cabalar (2009) presented two GP prediction models for damping ratio and shear modulus of sand-mica mixtures. Recently, Shahnazari et al. (2010) employed a variant of GP, namely multi expression programming for numerical modelling of the stress-strain behaviour of sand. Linear genetic programming (LGP) (Brameier, Banzhaf 2007) is a new subset of GP. LGP operates on computer programs that are represented as linear sequences of instructions of an imperative programming language (Brameier, Banzhaf 2001, 2007). In contrast with ANNs, GA and classical GP, applications of LGP to civil engineering problems are restricted to a few areas (Baykasoglu et al. 2008; Gandomi et al. 2010, 2011; Alavi, Gandomi 2011, 2012; Azmathulla et al. 2010, 2011).

This study aimed at utilizing the LGP approach to simulate the stress-strain behavior of sands subjected to a number of regular loading cycles. Alternative formulations to the rigorous conventional mathematical formulations were proposed for determining the damping ratio and shear modulus. A significant advantage of using LGP over the conventional models is that the damping ratio and shear modulus can be obtained independently of the form of the backbone curve. Therefore, there is no need to perform laboratory tests before the implementation of the LGP models.

\section{Linear genetic programming}

GP creates computer programs to solve a problem through simulating the biological evolution of living organisms (Koza 1992). Generally, in GP, inputs and corresponding output data samples are known and the main goal is to find a program that connects them (Weise 2009). Most of the genetic operators used in GA can be implemented in GP with minor changes. The main difference between GP and GA is the representation of the solution. GA creates a string of numbers that represent the solution. The classical GP solutions are computer programs represented as tree structures and expressed in a functional programming language (such as LISP) (Koza 1992; Alavi et al. 2011). In other words, in GP, the evolving programs (individuals) are parse trees than can vary in length throughout the run rather than fixed-length binary strings. The fitness of each program generated by GP is evaluated using a fitness function. Thus, the fitness function is the objective function that GP aims to optimize (Gandomi et al. 2011).

In addition to classical tree-based GP, there are other types of GP where programs are represented in different ways (Fig. 1). These are linear and graph-based GP(Banzhaf et al. 1998). Recently, several linear variants of GP have 


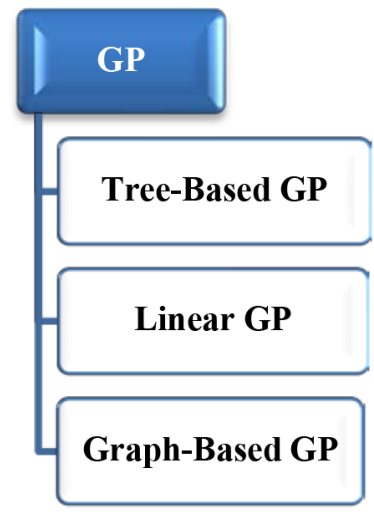

Fig. 1. Different types of genetic programming (Alavi, Gandomi 2011)

been developed such as linear genetic programming (LGP) (Brameier, Banzhaf 2007) and multi-expression programming (MEP) (Oltean, Grosan 2003). The linear variants of GP make a clear distinction between the genotype and phenotype of an individual. In these variants, individuals are represented as linear strings (Oltean, Grosan 2003). There are some main reasons for using linear GP. Computers do not naturally run tree-shaped programs. Therefore, slow interpreters have to be used as a part of classical tree-based GP. Conversely, by evolving the binary bit patterns, the use of an expensive interpreter is avoided. Consequently, a linear GP system can run several orders of magnitude faster than comparable interpreting systems. The enhanced speed of the linear variants of GP (e.g. LGP and MEP) permits conducting many runs in realistic timeframes. This leads to deriving consistent and high-precision models with little customization (Francone, Deschaine 2004; Poli et al. 2007; Gandomi et al. 2011).

LGP is a new subset of GP with a linear structure similar to the DNA molecule in biological genomes. In LGP, expressions of a functional programming language (such as LISP) are substituted by programs of an imperative language (such as $\mathrm{C} / \mathrm{C}++$ ) (Brameier, Banzhaf 2001, 2007). Figure 2 presents a comparison of structure of a program evolved by LGP and classical GP. As shown in this figure, a linear genetic program can be seen as a data flow graph generated by multiple usage of register content. In classical tree-based GP, the data flow is more rigidly determined by the tree structure of the program (Brameier, Banzhaf 2001; Gandomi et al. 2011).

(a)

$$
\begin{aligned}
& r[0]=0 ; \\
& r[0]+=r[0] \\
& r[0] \times=5 ; \\
& r[0]=\log (r[0])
\end{aligned}
$$

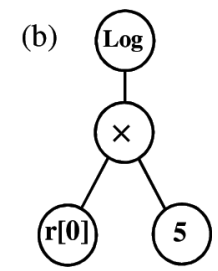

Fig. 2. A comparison of a GP program structure evolved by: a) LGP; b) Classical tree-based GP (after Gandomi et al. 2011)
In the LGP system described here, a program is interpreted as a variable-length sequence of simple $\mathrm{C}$ instructions. The instruction set or function set of LGP contains arithmetic operations, conditional branches, and function calls. The terminal set of the system is composed of variables and constants. The instructions are restricted to operations that accept a minimum number of constants or memory variables, called registers $(f)$, and assign the result to a destination register, e.g. $f_{0}:=f_{1}+1$. A part of a linear genetic program in $\mathrm{C}$ code is represented in Figure 3. In this figure, register $f[0]$ holds the final program output (Gandomi et al. 2010).

Here are the steps which the LGP system follows for a single run (Brameier, Banzhaf 2007; Gandomi et al. 2010):

1. Initializing a population of randomly generated programs and calculating their fitness values.

2. Running a Tournament. In this step four programs are selected from the population randomly. They are compared based on their fitness. Two programs are then picked as the winners and two as the losers.

3. Transforming the winner programs. After that, two winner programs are copied and transformed probabilistically into two new programs via crossover and mutation operators.

4. Replacing the loser programs in the tournament with the transformed winner programs. The winners of the tournament remain unchanged.

5. Repeating steps two through four until termination or convergence conditions are satisfied.

Crossover occurs between two or more instruction blocks whereas mutation occurs on a single instruction. Figure 4 demonstrates typical crossover and mutation in LGP. The crossover operation works by exchanging continuous sequences of instructions between parents. As it is seen in Figure 4(a), a segment of random position and arbitrary length is selected in each of the two parents $(f(0)$ and $g(0))$ and exchanged. If one of the two children would exceed the maximum length, crossover is aborted and restarted with exchanging equally sized segments (Brameier, Banzhaf 2001; Gandomi et al. 2011). Two commonly used types of standard LGP mutations are micro and macro mutation. The micro mutation changes an operand or an operator of an instruction. The macro mutation operation inserts or deletes a random instruction (Brameier, Banzhaf 2001; Gandomi et al. 2011).

L0: $f[0]-=\mathrm{v}[0] ;$
L1: $f[0]^{*}=3 ;$
L2: $f[0]=\mathrm{v}[2] ;$
L3: $f[0]+=\mathrm{v}[2] ;$
L4: $f[0]=3 ;$
L5: $f[0]=\cos (f[0]) ;$
L6: $f[0]+=f[0] ;$

Fig. 3. An excerpt of a linear genetic program 
(a)

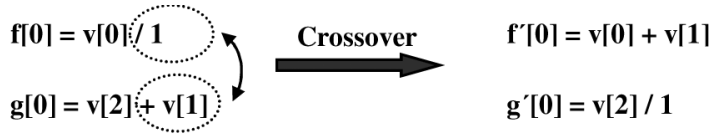

(b)

$\mathrm{f}[0]=\mathrm{v}[0] \mathrm{U} \mathrm{v}[1] \stackrel{\text { Mutation }}{\longrightarrow} \mathrm{f}^{\prime}[0]=\mathrm{v}[0]+\mathrm{v}[1]$

Fig. 4. Typical variation operations in LGP: (a) crossover; and (b) mutation

\section{Simulation of hysteresis stress-strain relationships}

The loading conditions and physical properties are proved to be important factors governing the stress-strain behaviour of sands under large amplitude cyclic loading (Ishihara 1996; Shahnazari, Towhata 2002; Shahnazari et al. 2010). During the cyclic shear, shear history and density notably affect the behaviour of sands. Further, the strain-stress relationship of soil depends on the strain amplitude and confining pressure. Effects of initial anisotropic stress state are important in the initial stage of loading (Shahnazari, Towhata 2002). The following parameters governing the hysteresis behaviour were identified as the inputs of the proposed models on the basis of a literature review (Ishihara 1996; Shahnazari, Towhata 2002; Shahnazari et al. 2010):

- $D_{r}$ : Initial relative density;

$-\gamma_{\max }$ : Strain amplitude;

$-\sigma_{c}^{\prime}$ : Initial confining pressure;

- $k$ : Initial anisotropic stress state $\left(\sigma_{c}^{\prime} / \sigma_{z}^{\prime}\right)$;

- $n$ : Shear history (number of cycles).

Shear history can be studied in terms of accumulated shear energy, number of cycles, cumulative shear strain increment and/or any combination of these parameters. Herein, the number of cycles was used as an index for shear history. To simulate the strain-stress relationship, general form of normalized hysteresis loops in loading phase is described by the following equation (Shahnazari et al. 2010):

$$
y=f(x),
$$

where: $x$ and $y$ are the normalized strain and stress, respectively. $x$ and $y$ are defined as follows:

$$
\begin{aligned}
& y=\frac{\tau}{\tau_{\max }} ; \\
& x=\frac{\gamma}{\gamma_{\max }},
\end{aligned}
$$

The general form of the normalized loops in unloading phase is consequently as follows (Ishihara 1996):

$$
-y=f(-x)
$$

where: $\vartheta_{\max }$ and $\gamma_{\max }$ are, respectively, the maximum shear stress and maximum shear strain at each cycle of

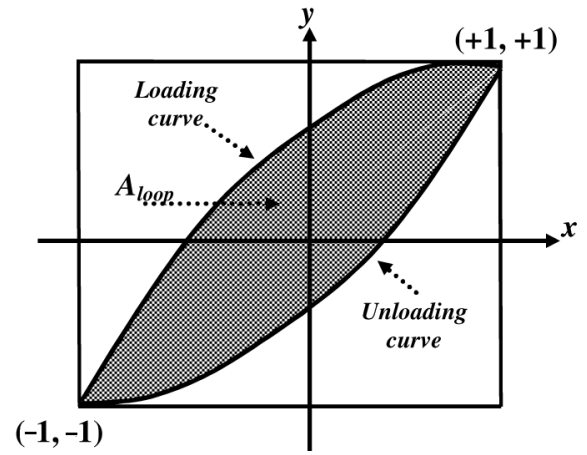

Fig. 5. A typical normalized hysteresis loop (Shahnazari et al. 2010)

each test. Figure 5 shows a typical normalized hysteresis loop in loading and unloading phases. $\vartheta_{\max }$ and $f$ are functions of several influencing parameters. The details of developing generalized relationships for $\vartheta_{\max }, f$, damping ratio, and shear modulus are provided in the following subsections.

The parameters used for measuring the performance of the proposed correlations were correlation coefficient (R), mean square error (MSE) and mean absolute error (MAE). R, MSE and MAE were calculated using the following equations:

$$
\begin{gathered}
R=\frac{\sum_{i=1}^{n}\left(h_{i}-\bar{h}_{i}\right)\left(t_{i}-\bar{t}_{i}\right)}{\sqrt{\sum_{i=1}^{n}\left(h_{i}-\bar{h}_{i}\right)^{2} \sum_{i=1}^{n}\left(t_{i}-\bar{t}_{i}\right)^{2}}} \\
M S E=\frac{\sum_{i=1}^{n}\left(h_{i}-\bar{h}_{i}\right)^{2}}{n} ; \\
M A E=\frac{\sum_{i=1}^{n}\left|h_{i}-\bar{h}_{i}\right|^{2}}{n}
\end{gathered}
$$

where: $h_{i}$ and $t_{i}$ are, respectively, the actual and predicted outputs for the $i$-th output, $\bar{h}_{i}$ and $\overline{t_{i}}$ are the average of the actual and predicted outputs, respectively. $n$ is the number of samples.

\subsection{Experimental database}

The results of several hollow torsional tests were used for the development of the LGP-based models. The employed experimental database has been previously presented by Shahnazari et al. (2010) to analyse the stress-strain behaviour of sand using the multi expression programming technique. Torsional shear apparatus was used to perform the tests. This apparatus can apply simultaneous triaxial and torsional modes of shearing to a hollow 
cylindrical specimen. This apparatus is basically composed of a triaxial cell, loading and measurement systems. Toyoura sand was used as the tested material for the experimental investigation. This material is classified as uniform clean fine sand consisting of sub-rounded to sub-angular particles. Toyoura sand consists mostly of quartz (around 90\%) and chert (around 4\%). The physical properties of this material and the grain size distribution curve can be found in Shahnazari et al. (2010). The specimens were prepared by the air-pluviation method. To prepare different relative density of specimens, the drop high and the rate of pluviation were changed. To reach a high degree of saturation, the carbonate dioxide $(\mathrm{CO} 2)$ and then de-aired water were percolated through the specimens. Afterwards, to achieve the B-value 0.98 a saturation back pressure of $100 \mathrm{kPa}$ applied. Thereafter, the specimens were consolidated under different anisotropic consolidation ratio and confining pressure. At the loading stage, specimens were sheared under a drained cyclic torsional method. The conducted tests were straincontrol and the strain amplitude maintained constant during the cyclic loading of each test. The torsional shear strain rate was $0.3 \% / \mathrm{min}$ and drainage condition was imposed (Shahnazari et al. 2010). Comprehensive information about the details of performing the hollow torsional tests, experimental equipment, loading ranges, etc. can be found in Ishihara (1996), Shahnazari and Towhata (2002) and Shahnazari et al. (2010). The database used in this study includes a total of 22 cyclic torsional simple shear tests performed on loose to medium dense saturated samples of Toyoura sand. It contains the measurements of $D_{r}, \gamma_{\max }(\%), \sigma_{c}^{\prime}(\mathrm{kPa}), k$ and $\tau_{\max }(\mathrm{kPa})$ at different loading cycles $(n)$. Of more than 31000 data records, 746 records pertaining to $\vartheta_{\max }$ at each test, loading cycles were extracted for developing the $\vartheta_{\max }$ predictive models. The statistics of different parameters involved in the model development are given in Table 1.

\subsection{Explicit formulation of normalized stress-strain relationship}

The general form of the hysteresis loop was taken into account to construct a predictive correlation for $f$. The formulation of $f$ was considered to be as follows:

Table 1. The variables used in model development

\begin{tabular}{lcccccc}
\hline Parameter & $D_{r}$ & $\begin{array}{c}\gamma_{\max } \\
(\%)\end{array}$ & $\sigma^{\prime}{ }_{c}(\mathrm{kPa})$ & $K$ & $n$ & $\begin{array}{c}\tau_{\max } \\
(\mathrm{kPa})\end{array}$ \\
\hline Mean & 0.45 & 2.15 & 101 & 1.1 & 24 & 70.09 \\
\hline $\begin{array}{l}\text { Standard } \\
\text { Error }\end{array}$ & 0.01 & 0.04 & 0.82 & 0.02 & 0.97 \\
\hline $\begin{array}{l}\text { Standard } \\
\text { Deviation }\end{array}$ & 0.21 & 1.22 & 22.14 & 0.41 & 26.38 \\
\hline $\begin{array}{l}\text { Sample } \\
\text { Variance }\end{array}$ & 0.04 & 1.48 & 490.17 & 0.17 & 696.08 \\
\hline Minimum & 0.19 & 0.51 & 53 & 0.3 & 1 & 31.40 \\
\hline Maximum & 0.78 & 6.01 & 183.7 & 2.5 & 65 & 150.50 \\
\hline
\end{tabular}

$$
f(x)=f\left(\frac{\gamma}{\gamma_{\max }}\right)=\frac{a\left(\frac{\gamma}{\gamma_{\max }}\right)+b}{c\left(\frac{\gamma}{\gamma_{\max }}\right)^{2}+d\left(\frac{\gamma}{\gamma_{\max }}\right)+e},
$$

where:

$$
\begin{gathered}
a=a_{1} D_{r}+a_{2} \gamma_{\text {max }}+a_{3} \sigma_{c}^{\prime}+a_{4} k ; \\
b=b_{1} D_{r}+b_{2} \gamma_{\text {max }}+b_{3} \sigma_{c}^{\prime}+b_{4} k ; \\
c=c_{1} D_{r}+c_{2} \gamma_{\text {max }}+c_{3} \sigma_{c}^{\prime}+c_{4} k ; \\
d=b ; \\
e=a-c ;
\end{gathered}
$$

$a, b, c, d$ and $e$ were considered as linear factions of the loading conditions and physical properties $\left(D_{r},{ }_{\max }, \sigma_{c}^{\prime}\right.$, $k$ ). The coefficients $d$ and $e$ were determined in a way that points $(+1,+1)$ and $(-1,-1)$ satisfy Eqn (1) (Fig. 5). The normalized stress-strain relationship for unloading phase can simply be obtained according to the definition of Eqn (4) (Shahnazari et al. 2010). The coefficients $a_{i}, b_{i}$ and $c_{i}$ $(\mathrm{i}=1, \ldots, 5)$ were obtained using genetic algorithm (GA) (Goldberg 1989). GA is a powerful and broadly applicable stochastic search and optimization technique based on the mechanisms of natural selection and natural genetics. Although much attention has been given to GA as an optimization tool, it is widely applicable in developing models to fit data. The following objective function was built as a measure of how well the model predicted output agrees with the experimentally measured output. Then, a GA-based search was conducted to find the coefficients that minimize this function:

$$
\text { Objective Function }=\frac{M A E}{R^{2}},
$$

where: $\mathrm{R}$ and MAE are, respectively, the correlation coefficient and the mean absolute error. $h_{i}$ and $t_{i}$ are as follows:

$$
\begin{gathered}
h_{i}=\left(\frac{\tau}{\tau_{\max }}\right)_{\text {Experiment }, i} ; \\
t_{i}=\left(\frac{\tau}{\tau_{\max }}\right)_{\text {Predicted }, i}=f\left(\frac{\tau}{\tau_{\max }}\right)_{i} .
\end{gathered}
$$

$\bar{h}_{i}$ and $\bar{t}_{i}$ are the average of the actual and the calculated outputs, and $n$ is the number of samples. The selection of the GA settings requires careful consideration since it is problem-dependent and tends to ultimately control the performance of GA. Despite the existence of some rules of thumb, such as high levels of mutation tend to disorganize the convergence on the solution; it is the responsibility of the experimenter to decide on appropriate values 
for the crossover rate, and mutation rate. The appropriate selection of these parameters along with the population size is essential for the successful performance of GA. The final settings used in the present genetic algorithm are presented in Table 2. The optimal values of the coefficients obtained by GA are shown in Table 3. As presented in Table 4, the developed function $f$ has a very good prediction performance.

\subsection{Explicit formulation of maximum shear stress}

In this phase, LGP was utilized to obtain a meaningful relationship between $\vartheta_{\max }$ and several influencing parameters. The formulation of $\vartheta_{\max }$ was considered to be as follows:

$$
\tau_{\max }=f\left(D_{r}, \gamma_{\max }, \sigma_{c}^{\prime}, k, n\right)
$$

For the LGP analysis, holdout method was used. The holdout method is one of the most well-known kinds of

Table 2. Parameter settings for GA

\begin{tabular}{lc}
\hline Parameter & Settings \\
\hline Population size & 100 \\
\hline Population type & Double vector \\
\hline Maximum generations & 250 \\
\hline Migration & \\
\hline Direction & Forward \\
\hline Fraction & 0.2 \\
\hline Interval & 20 \\
\hline Crossover rate & Scattered \\
\hline Mutation rate & 0.01 \\
\hline
\end{tabular}

Table 3. The optimal values of the coefficients

\begin{tabular}{cc}
\hline Coefficient & Optimal value \\
\hline$a_{1}$ & 0.14 \\
\hline$a_{2}$ & -1.7 \\
\hline$a_{3}$ & 0.8 \\
\hline$a_{4}$ & 0.96 \\
\hline$b_{1}$ & -1.71 \\
\hline$b_{2}$ & -0.39 \\
\hline$b_{3}$ & -0.14 \\
\hline$b_{4}$ & 1.4 \\
\hline$c_{1}$ & 0.39 \\
\hline$c_{2}$ & 0.31 \\
\hline$c_{3}$ & 0.53 \\
\hline$c_{4}$ & 1.16 \\
\hline
\end{tabular}

Table 4. Overall performance of the proposed formulation of the normalized strain-stress relationship

\begin{tabular}{lccc}
\hline \multirow{2}{*}{ Model } & \multicolumn{3}{c}{ All elements } \\
\cline { 2 - 4 } & $\mathrm{R}$ & MSE & MAE \\
\hline$f($ ), Eqn (8) & 0.988 & 0.005 & 0.48 \\
\hline
\end{tabular}

cross validation. On this basis, the experimental database was randomly divided into training and testing subsets. Hold-out validation avoids the overlap between training data and testing data, yielding a more accurate estimation for the generalization performance of the algorithm. The advantage of this method is that it takes less time to compute compared with the other cross validation procedures (e.g. K-fold) (Refaeilzadeh et al. 2009). In order to come up with a consistent data division, several combinations of the training and testing sets were considered. The maximum, minimum and mean of the parameters were consistent in the training and testing data sets. Of the 746 data, 560 data sets were used for the training process and 186 sets were taken for the testing of the LGP-based correlations. The best LGP-based formula was chosen on the basis of a multi-objective strategy as below:

1. Finding the simplest model, although this was not a predominant factor.

2. Providing the best fitness value on the training data. Various LGP involved parameters are shown in Table 5. The parameter selection will affect the generalization capability of the LGP models. Several runs were conducted to obtain a parameterization of LGP that provided enough robustness and generalization to solve the problem. Three levels were set for the population size and two levels were considered for the crossover rate and mutation rate. The success of the LGP algorithm usually increases when increasing the initial and maximum program size parameters. In this case, the complexity of the evolved functions increases and the speed of the algorithm decreases. The initial and maximum program sizes were respectively set to optimal values of 80 and 256 bytes as tradeoffs between the running time and the complexity of the evolved solutions. The number of demes was set to 20 . This parameter is related to the way that the population of programs is divided. Note that demes are semi-isolated subpopulations and evolution proceeds faster in them compared with a single population of equal size (Brameier, Banzhaf 2007). There are $3 \times 2 \times 2=12$ different combinations of the parameters. All of these parameter

Table 5. Parameter settings for the LGP algorithm

\begin{tabular}{lc}
\hline Parameter & Settings \\
\hline Function set &,,$+- \times, /$ \\
\hline Population size & $1000,2000,3000$ \\
\hline Maximum program size & 256 \\
\hline Initial program size & 80 \\
\hline Crossover rate (\%) & 50,95 \\
\hline Homologous crossover (\%) & 95 \\
\hline Mutation rate (\%) & 50,90 \\
\hline Block mutation rate (\%) & 30 \\
\hline Instruction mutation rate (\%) & 30 \\
\hline Data mutation rate (\%) & 40 \\
\hline Number of demes & 20 \\
\hline
\end{tabular}


combinations were tested and 10 replications for each were carried out. Therefore, the overall number of runs was equal to $12 \times 10=120$ for each of the input combinations. A fairly large number of tournaments (900000) were tested on each run to find a model with minimum error. For each case, the program was run until there was no more significant improvements in the performance of the models or the run terminated automatically. For the LGP-based analysis, the Discipulus software (Conrads et al. 2004) was used. The contributions of the predictor variables in the best LGP model were evaluated through a sensitivity analysis. To perform the sensitivity analysis, frequency values of the input parameters were obtained. A frequency value equal to $100 \%$ for an input indicates that this variable has appeared in $100 \%$ of the best thirty programs evolved by LGP. This is a common approach in the GP-based analyses (Gandomi et al. 2010, 2011).

The LGP-based formulation of $\vartheta_{\max }(\mathrm{kPa})$ in terms of the independent variables is as given below:

$\tau_{\max }=\frac{1}{4} \frac{\left(\frac{D_{r}}{k^{2}}-1\right) \times \sigma_{c}^{\prime}}{\gamma_{\max }}+\frac{1}{4} n k-\frac{1}{4} \sigma_{c}^{\prime} k+9 D_{r}+\sigma_{c}^{\prime}$,

where: $D_{r}, \sigma_{c}^{\prime}, \gamma_{\max }, k$ and $n$ denote the initial relative density, initial effective confining pressure, strain amplitude, initial anisotropic stress state, and number of cycles, respectively. A comparison of the LGP predicted and experimental $\vartheta_{\max }$ for the training and testing data sets is shown in Figure 6. Performance statistics of the proposed LGP-based formula on the entire database are summarized in Table 7. The results clearly demonstrate that the proposed correlation provides accurate predictions of $\vartheta_{\max }$. The frequency values of the input parameters are presented in Figure 7. According to this figure, $\vartheta_{\max }$ is more sensitive to $\gamma_{\max }$ and $k$ compared with the other inputs.

Table 6. Overall performance of the proposed LGP model

\begin{tabular}{lccc}
\hline \multirow{2}{*}{ Model } & \multicolumn{3}{c}{ All elements } \\
\cline { 2 - 4 } & $\mathrm{R}$ & MSE & MAE \\
\hline$\tau_{\max }$, Eqn $(18)$ & 0.978 & 30.37 & 4.11 \\
\hline
\end{tabular}

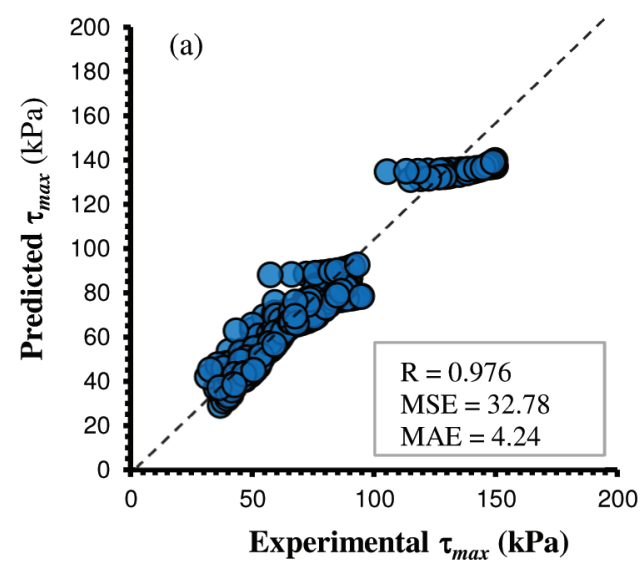

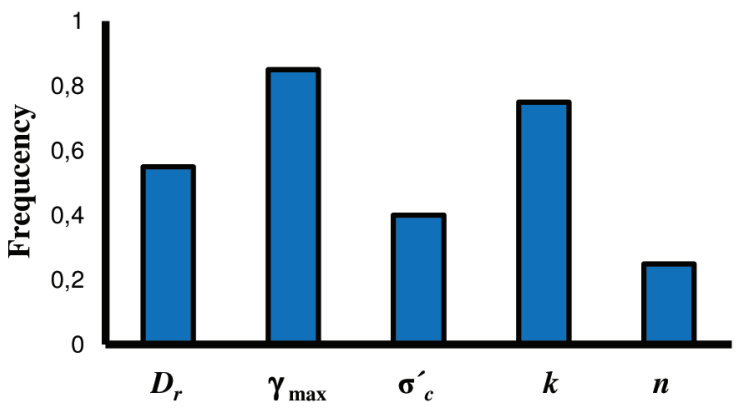

Fig. 7. Contributions of the predictor variables in the LGP analysis

Table 7. Overall performance of the proposed formulation of strain-stress relationship

\begin{tabular}{cccc}
\hline \multirow{2}{*}{ Model } & \multicolumn{3}{c}{ All elements } \\
\cline { 2 - 4 } & $\mathrm{R}$ & MSE & MAE \\
\hline$\tau$, Eqn (19) & 0.953 & 60.52 & 5.96 \\
\hline
\end{tabular}

\subsection{Explicit formulation of strain-stress relationship}

A generalized formulation was developed for strainstress curves. The final form of the hysteresis curves after substituting $f$ and $\vartheta_{\max }$ into Eqn (1) is as follows:

$$
\tau=\left\{\begin{array}{cc}
\tau_{\max } \frac{A\left(\frac{\gamma}{\gamma_{\max }}\right)+B}{C\left(\frac{\gamma}{\gamma_{\max }}\right)^{2}+B\left(\frac{\gamma}{\gamma_{\max }}\right)+A-C} & \text { (Loading) } \\
\tau_{\max } \frac{\gamma\left(\frac{\gamma}{\gamma_{\max }}\right)-B}{C\left(\frac{\gamma}{\gamma_{\max }}\right)^{2}-B\left(\frac{\gamma}{\gamma_{\max }}\right)+A-C} & \text { (Unloading) }
\end{array},\right.
$$

where:

$$
A=0.14 D_{r}-1.70 \gamma_{\max }+0.80 \sigma_{c}^{\prime}+0.96 k
$$

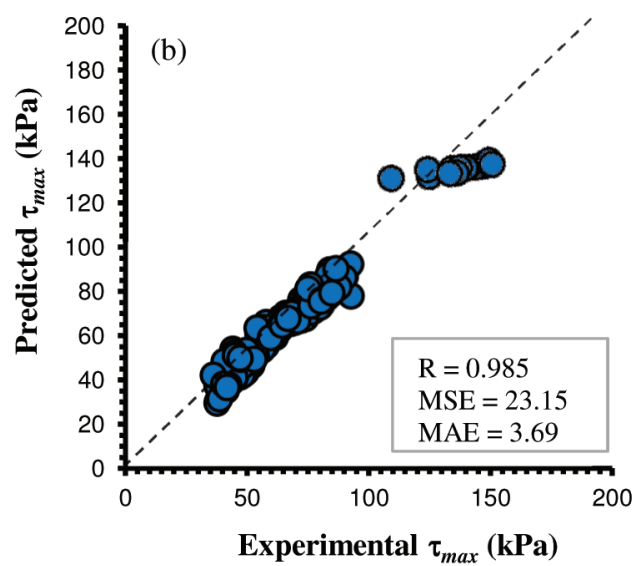

Fig. 6. Experimental versus predicted $\vartheta_{\max }$ values using the LGP model: a) training data; b) testing data 


$$
\begin{aligned}
& B=-1.71 D_{r}-0.39 \gamma_{\max }-0.14 \sigma_{c}^{\prime}-1.40 k ; \\
& C=0.39 D_{r}+0.31 \gamma_{\max }+0.53 c_{3} \sigma_{c}^{\prime}+1.16 k,
\end{aligned}
$$

and $\vartheta_{\max }$ can be obtained using Eqn (18). Two curves produced by Eqn (19) are identical to each other except for the rotation by $180^{\circ}$ and translation. A typical comparison of the model simulations with laboratory results at different conditions, for eight tests, is shown in Figure 8. As it is seen, the simulations are in good agreement with real experimental curves. Furthermore, the overall trends of these figures agree with well-known observations. The observed deviation between predicted and measured stress-strain curves is not only due to model deficiency but partly due to uncertainties, errors and inconsistencies in the data employed for the training and testing purposes.
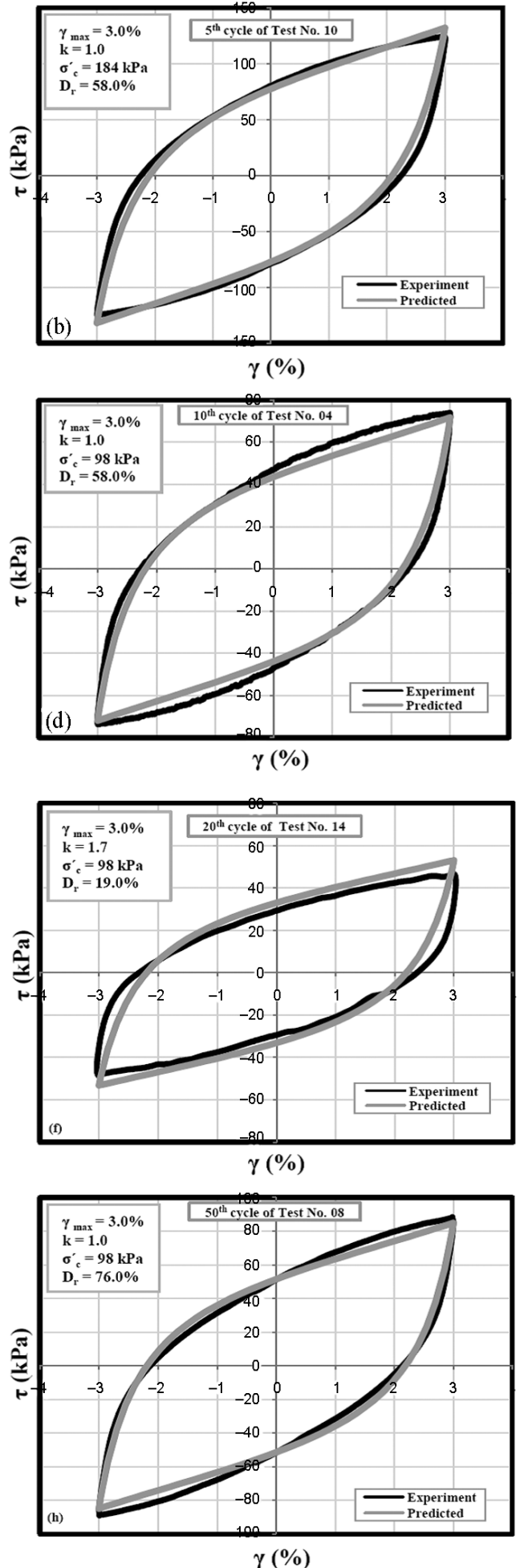

Fig. 8. Experimental hysteresis curves versus predicted curves 
It is known that two identical experiments do not normally produce identical stress-strain results, especially for frictional materials such as sandy soils (Shahnazari et al. 2010). Performance statistics of the correlation on the entire database is shown in Table 8. It can be observed that the proposed correlation provides accurate predictions of the shear stress.

\subsection{Explicit formulation of damping ratio and shear modulus}

The hysteresis curves were constructed for the strainstress relationship in a way that they produce the damping ratio $(D)$ and shear modulus $(G)$. By applying the formulation of the developed hysteresis loops (Eqn (19)) to the definition of $D$ and $G$, the following constitutive correlations were obtained:

$$
\begin{gathered}
D=\frac{W_{l}}{4 \pi W}=\frac{A_{\text {loop }}}{4 \pi\left(\frac{1}{2} \cdot \tau_{\max } \cdot \gamma_{\max }\right)}=\frac{A_{\text {loop }}}{2 \pi \cdot \tau_{\max } \cdot \gamma_{\max }}, \\
G=\frac{\tau_{\max }}{\gamma_{\max }}
\end{gathered}
$$

where:

$$
\begin{gathered}
A_{\text {loop }}=\tau_{\max } \cdot \gamma_{\max } \\
{\left[\int_{-1}^{+1} \frac{a X+b}{c X^{2}+b X+a-c}-\int_{-1}^{+1} \frac{a X-b}{-c X^{2}+b X-a+c}\right],} \\
A_{\text {loop }}=\tau_{\text {max }} \cdot \gamma_{\max } \frac{a}{2 c}\left[\ln \left(\frac{a+b}{a-b}\right)+\frac{\frac{2 b}{a}+\frac{b}{c}}{2 \sqrt{\frac{b^{2}}{4 c^{2}}-\frac{a-c}{c}}} \times\right. \\
\left.\ln \left(\frac{\left(1+\frac{b}{2 c}-I\right) \times\left(-1+\frac{b}{2 c}+I\right)}{\left(1+\frac{b}{2 c}+I\right) \times\left(-1+\frac{b}{2 c}-I\right)}\right)\right],
\end{gathered}
$$

and

$$
I=\sqrt{\frac{b^{2}}{4 c^{2}}-\frac{a-c}{c}}
$$

where: $W_{l}=$ dissipated energy; $W=$ elastic strain energy; $A_{\text {loop }}=$ area surrounded by the hysteresis loop; and $A_{s}=$ area of the shaded triangular shown in Figure 9 (Zhang et al. 2005; Shahnazari et al. 2010). $A_{\text {loop }}$ was obtained by integrating from the developed hysteresis curve formulation (Shahnazari et al. 2010). As mentioned before, the previous constitutive models need calibration parameters that should be obtained from at least one laboratory test. Therefore, it was not possible to conduct a comparative

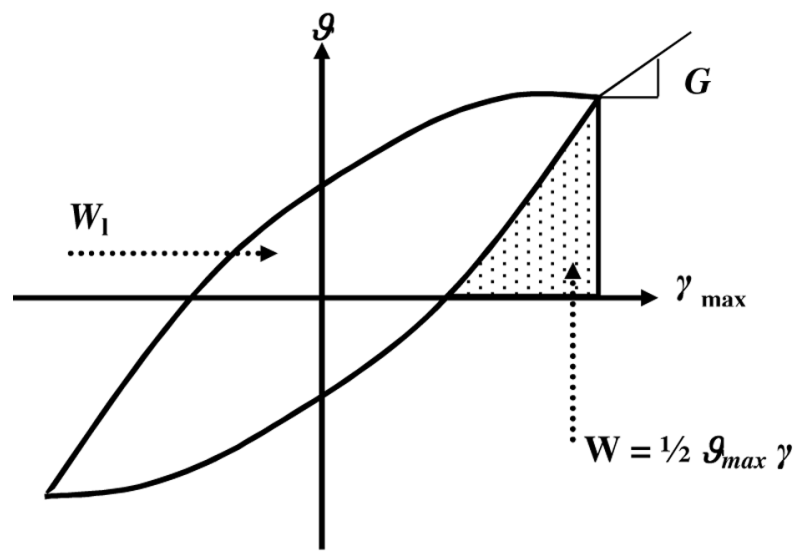

Fig. 9. Stress-strain relationships at different strain amplitude showing $D$ and $G$ (Zhang et al. 2005)

study between the proposed model and any of the existing models.

\section{Validity verification}

The validity of the LGP-based model for the strain-stress relationship was verified by applying it to simulate the stress-strain curves for portions of laboratory results which were not included in the training process. The predictions made by the proposed model are shown in Figure 10. It can be observed from this figure that the simulated curves by the suggested model are in a good agreement with the experimental curves. This concludes that this model is efficient in predicting the stress-strain curve of sandy soils.

\section{Parametric analysis}

For further verification of the robustness of the proposed correlations, a parametric analysis was performed in this study. The main goal is to find the effect of each parameter on the maximum shear stress $\left(\vartheta_{\max }\right)$ and on the developed hysteresis loops. In order to conduct a fair comparison, the results for the hystersis loops at a particular loading cycle $\left(10^{\text {th }}\right.$ cycle) are presented. Further, damping ratio and shear modulus reduction curves were plotted. It is well-known that the robustness of a design equation can be determined by examining how well the predicted values agree with the underlying physical behaviour of the investigated system (Kuo et al. 2009; Alavi et al. 2012).

Figures 11 and 12 present the predicted $\vartheta_{\max }$ and hysteresis curves as functions of the $\sigma_{c}^{\prime}, D_{r}, k, \gamma_{\max }$, and $n$. Figures 13 and 14 demonstrate the $G$ reduction and $D$ curves, respectively. As can be seen in Figure 11, $\vartheta_{\max }$ continuously increases due to increasing $D_{r}, \gamma_{\max }, \sigma_{c}^{\prime}$, $n$, and decreases with increasing $k$. Similar trends can be observed from Figure 12 for the developed hysteresis loops. The results of the parametric study for these loops are in acceptable agreement with the experimental overall trends shown in Figure 8. It is widely known that increases in the shear strain respectively decreases and increases $G$ and $D$. As shown in Figures 13 and 14, the results of parametric study for $G$ and $D$ are in close agreement with this reality. The results demonstrate that 

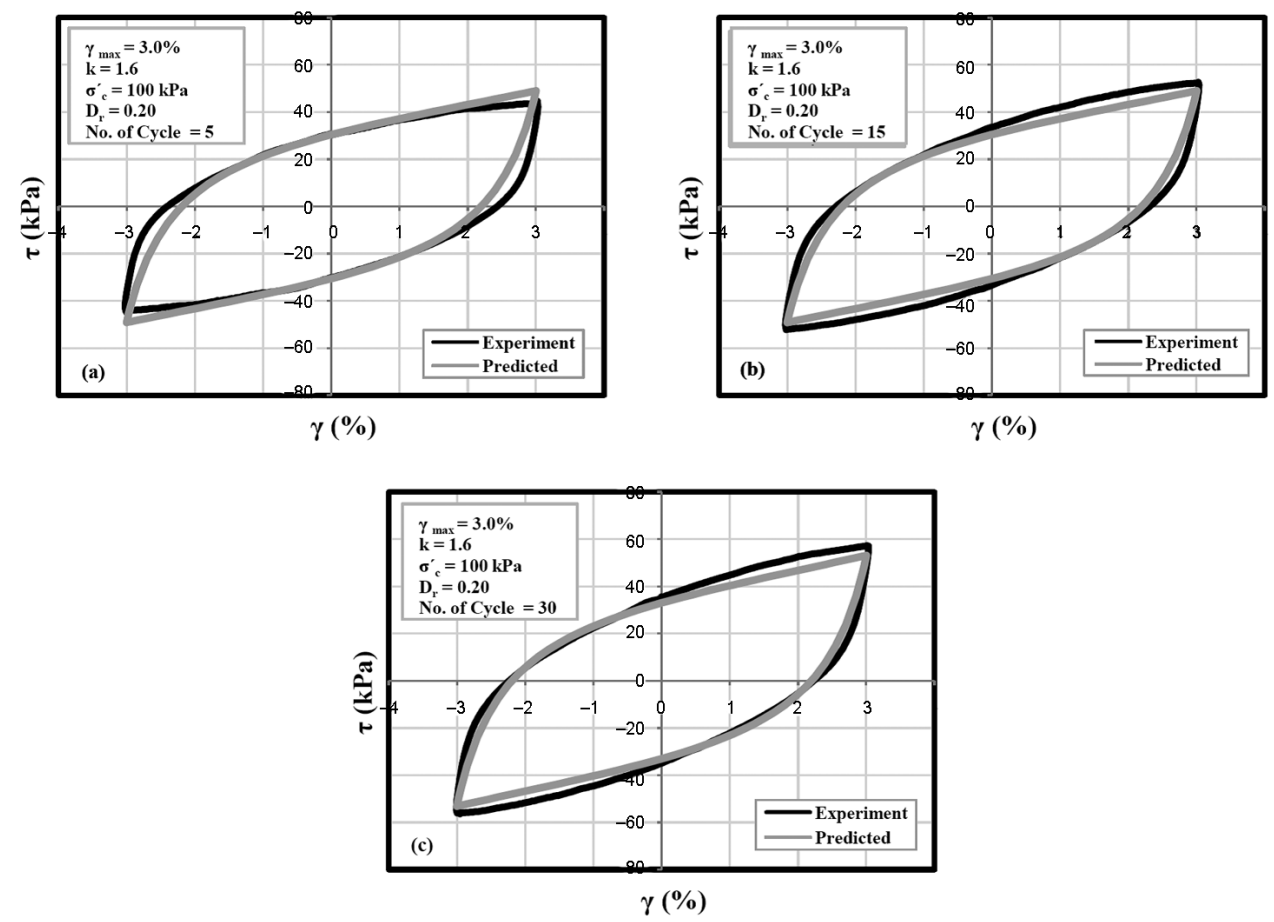

Fig. 10. Experimental hysteresis curves versus predicted curves for the validation data
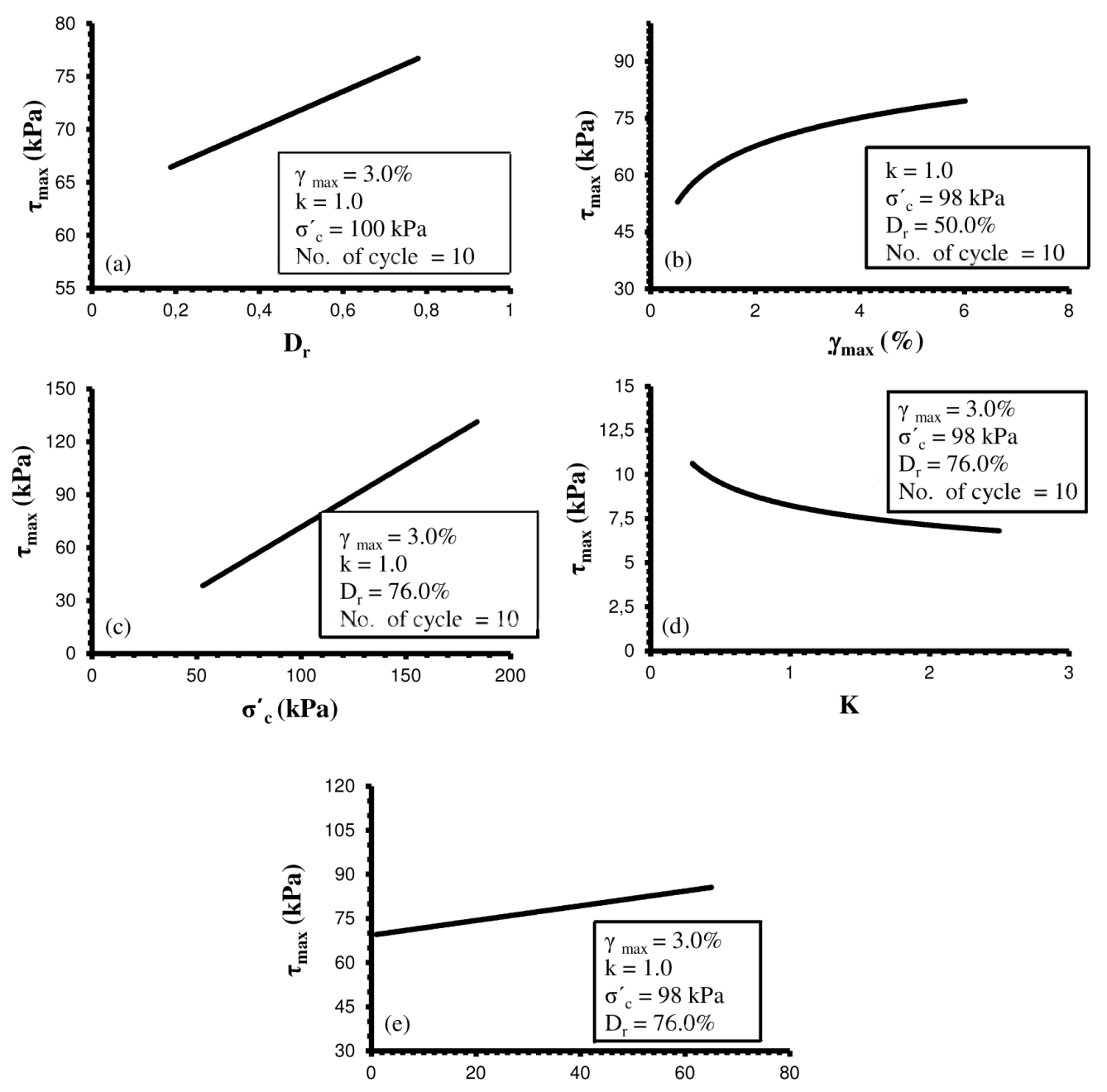

No. of Cycles

Fig. 11. Parametric analysis of the maximum shear stress 

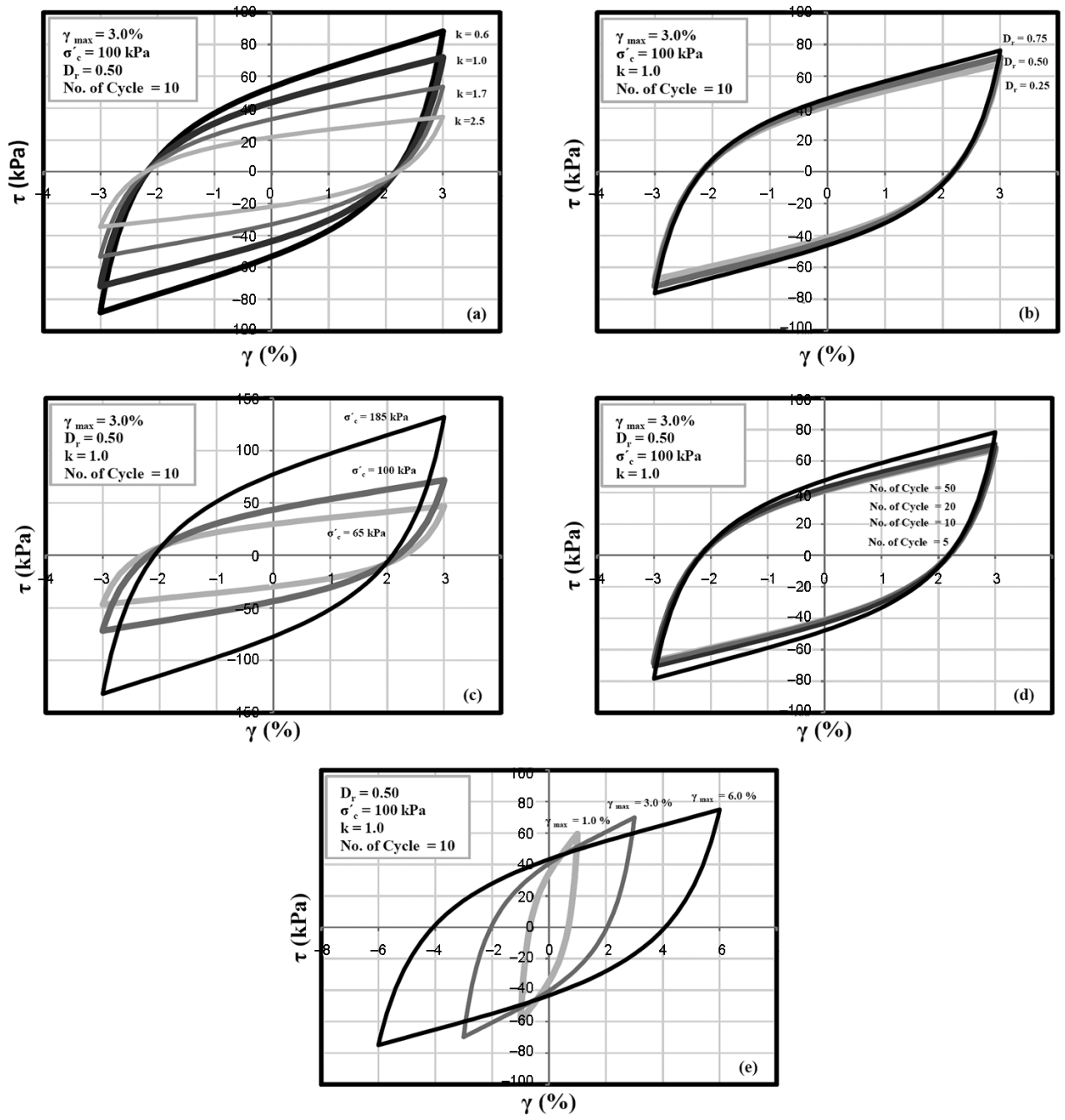

Fig. 12. Parametric analysis of the developed hysteresis loop
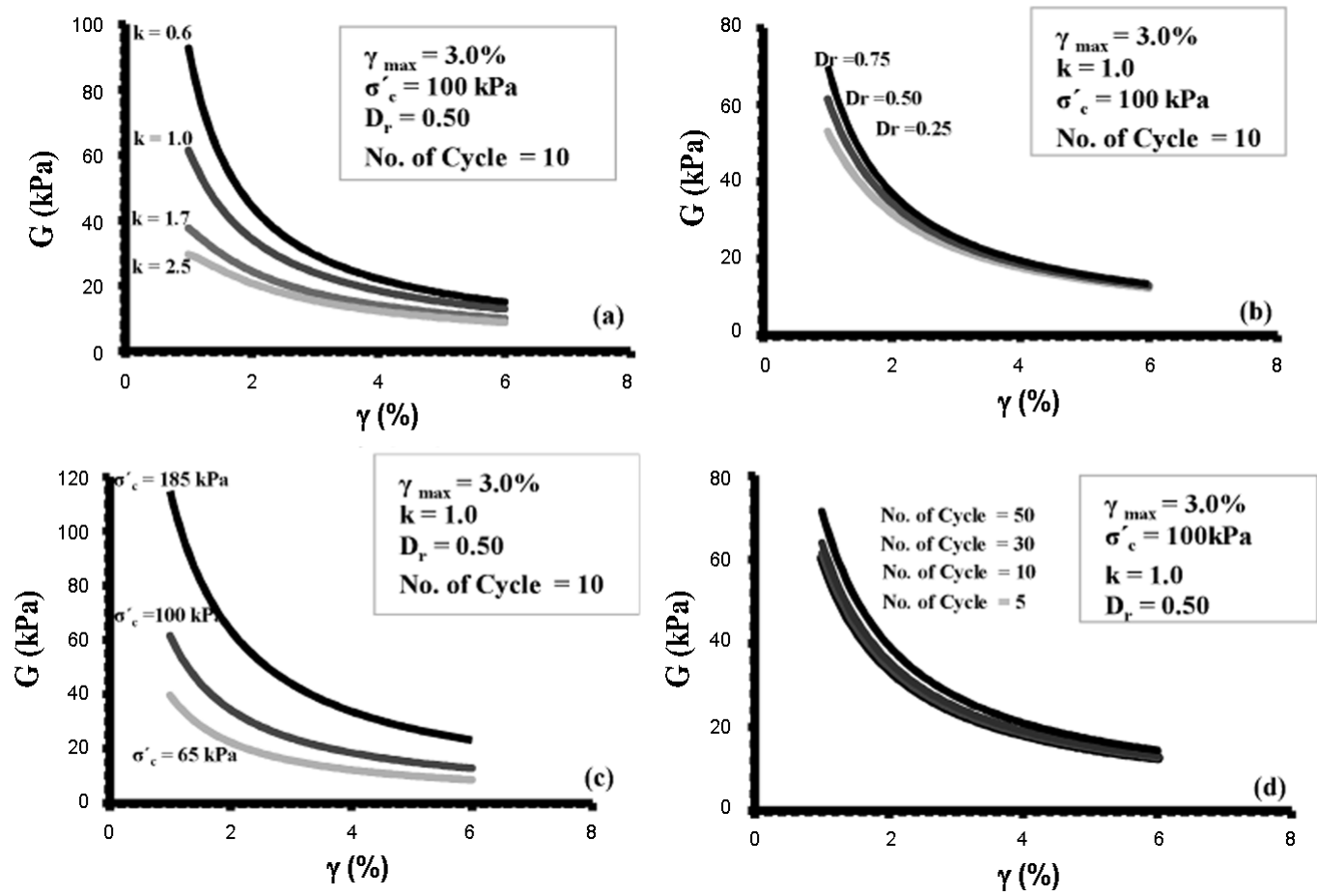

Fig. 13. Shear modulus versus shear strain 

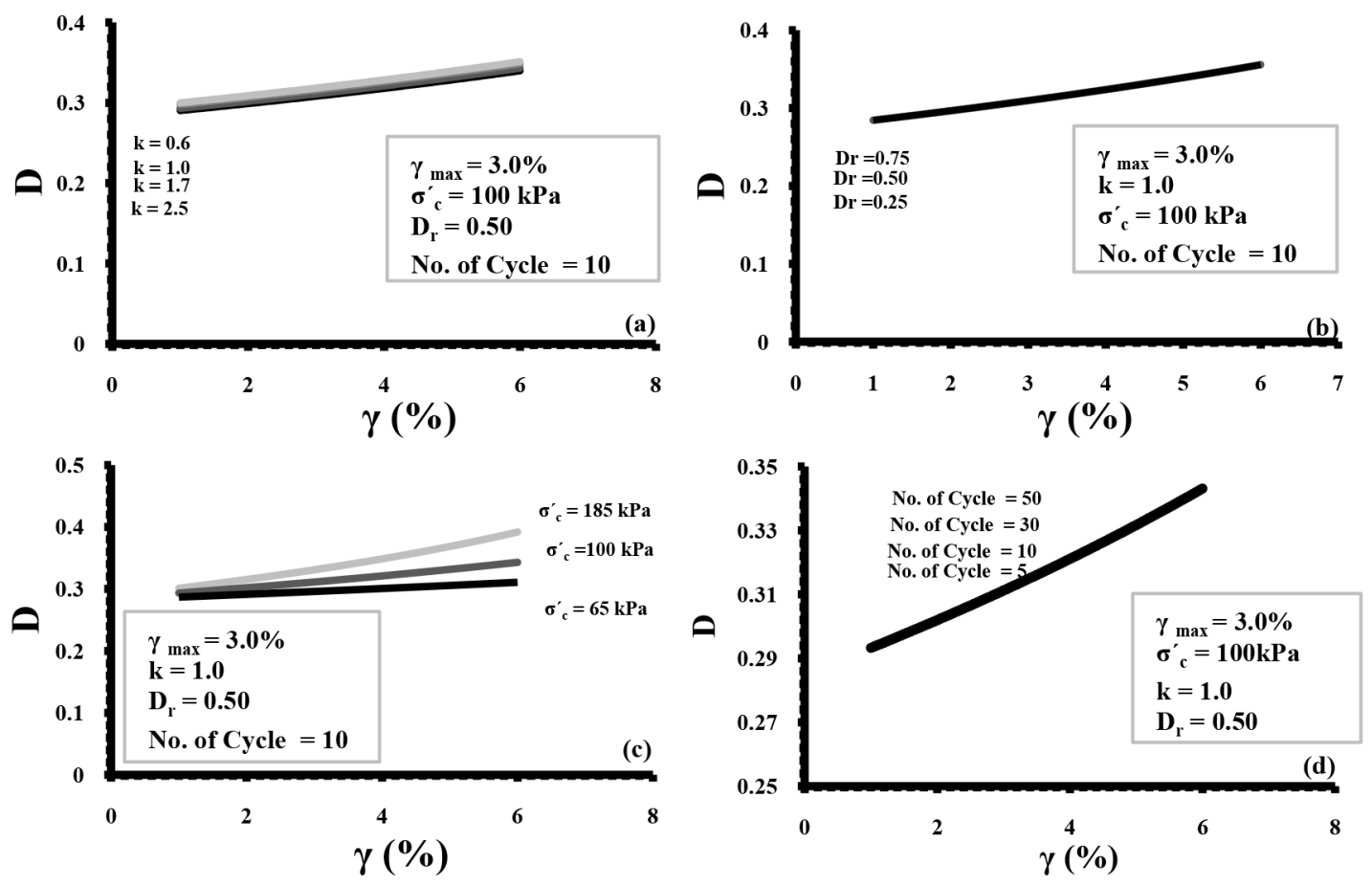

Fig. 14. Damping ratio versus shear strain

$G$ increases with increasing $D_{r}$ and $\sigma_{c}^{\prime}$ and decreases with increasing $k$. A significant property of sand is related to the densification and hardening behaviour under repeated loadings (Pradhan 1989). As shown in Figure 13(d), $G$ continuously increases with increasing $n$ which clearly represents the cyclic hardening behaviour of sand. It is obvious that the increment and decrement rates decline for larger shear strains. It can also be seen that, within the investigated range of shear strain, $D$ is not much sensitive to the changes in $D_{r}, \sigma_{c}^{\prime}$, and $n$. As can be observed from Figures 11-14, the results of the parametric study are soundly expected cases from a geotechnical viewpoint. This indicates that the developed correlations are robust and efficaciously incorporate the underlying physical relations governing the stress-strain behaviour of sand.

\section{Conclusions}

The behaviour of soil under the state of unloading and reloading is particularly important in many cases such as foundation excavation and cyclic loading. In this research, the LGP paradigm was employed for the analysis of the stress-strain behaviour of sands under large amplitude regular cyclic loading. A generalized predictive correlation for the hysteresis strain-stress curves was developed. An LGP-based relationship between the maximum shear stress and the influencing parameters $\left(D_{r}, \gamma_{\max }, \sigma_{c}^{\prime}, k, n\right)$ was established to construct the hysteresis curves. New empirical correlations were subsequently obtained for the damping ratio and shear modulus using the hysteresis curves formulation. A series of torsional simple shear tests performed on loose to medium dense samples of Toyoura sand were used to develop the correlations. The proposed correlations were found to be capable of simulating the hysteresis curves with reasonable accuracy. The developed formulations gave reliable predictions of the maximum shear stress and normalized stress-strain relationships. The proposed models are applicable to quartz sandy soils with physical properties similar to those of Toyoura sand used in this study. Unlike majority of the conventional approaches for constitutive modelling, the proposed models directly incorporate the key role of progression of cycles and other loading conditions and physical properties. Using the proposed LGP-based models, the damping ratio and shear modulus can be obtained independently of the form of the backbone curve. Therefore, unlike the conventional models, there is no need to go through very sophisticated and time-consuming laboratory experiments before implementing the LGP model. Based on the results of the sensitivity analysis, $\gamma_{\max }$ and $k$ were found to be more effective to explain the variations of the maximum shear stress compared with the other parameters. The validity verification phases confirmed that the models can effectively be used to simulate the soil stress-strain relationships beyond the training data domain. Based on the results of the parametric analysis, $G$ continuously increases with increasing $n$. This indicates that the cyclic hardening behaviour of sand was wellcaptured by the correlations. 


\section{References}

Alavi, A. H.; Ameri, M.; Gandomi, A. H.; Mirzahosseini, M. R. 2011. Formulation of flow number of asphalt mixes using a hybrid computational method, Construction and Building Materials 25(3): 1338-1355.

http://dx.doi.org/10.1016/j.conbuildmat.2010.09.010

Alavi, A. H.; Gandomi, A. H. 2011. A robust data mining approach for formulation of geotechnical engineering systems, International Journal of Computer Aided Methods in Engineering, Engineering Computations 28(3): 242-274. http://dx.doi.org/10.1108/02644401111118132

Alavi, A. H.; Gandomi, A. H. 2012. Energy-based models for assessment of soil liquefaction, Geoscience Frontiers 3(4): 541-555. http://dx.doi.org/10.1016/j.gsf.2011.12.008

Alavi, A. H.; Gandomi, A. H.; Mousavi, S. M. 2012. Discussion on prediction of shear strength parameters of soils using artificial neural networks and multivariate regression methods, Engineering Geology 137-138: 107-108. http://dx.doi.org/10.1016/j.enggeo.2012.03.011

Azamathulla, H. Md.; Ab Ghani, A.; Zakaria, N. A.; Guven, A. 2010. Genetic programming to predict bridge pier scour, ASCE Journal of Hydraulic Engineering 136(3): 165-169. http://dx.doi.org/10.1061/(ASCE)HY.1943-7900.0000133

Azamathulla, H. Md.; Deo, M. C.; Deolalikar, P. B. 2006. Estimation of scour below spillways using neural networks, Journal of Hydraulic Research 44(1): 61-69. http://dx.doi.org/10.1080/00221686.2006.9521661

Azamathulla, H. Md.; Guven, A.; Demir, Y. K. 2011. Linear genetic programming to scour below submerged pipeline, Ocean Engineering 38(8-9): 995-1000. http://dx.doi.org/10.1016/j.oceaneng.2011.03.005

Azmathulla, H. Md.; Deo, M. C.; Deolalikar, P. B. 2005. Neural networks for estimation of scour downstream of a skijump bucket, Journal of Hydraulic Engineering 131(10): 898-908

http://dx.doi.org/10.1061/(ASCE)0733-9429(2005)131:10(898)

Banimahd, M.; Yasrobi, S. S.; Woodward, P. K. 2005. Artificial neural network for stress-strain behavior of sandy soils: knowledge based verification, Computers and Geotechnics 32(5): 377-386. http://dx.doi.org/10.1016/j.compgeo.2005.06.002

Banzhaf, W.; Nordin, P.; Keller, R.; Francone, F. 1998. Genetic programming - An introduction on the automatic evolution of computer programs and its application. San Francisco: dpunkt/Morgan Kaufmann.

Bardet, J. P. 1995. Scaled memory model for cyclic behavior of soils, Journal of Geotechnical and Geoenvironmental Engineering ASCE 121(11): 766-775.

http://dx.doi.org/10.1061/(ASCE)0733-9410(1995)121:11(766)

Basheer, I. A. 2000. Selection of methodology for neural network modeling of constitutive hystereses behavior of soils, Computer-Aided Civil and Infrastructure Engineering 15(6): 440-458. http://dx.doi.org/10.1111/0885-9507.00206

Basheer, I. A. 2002. Stress-strain behavior of geomaterials in loading reversal simulated by time-delay neural networks, Journal of Materials in Civil Engineering ASCE 14(3): 270-273.

http://dx.doi.org/10.1061/(ASCE)0899-1561(2002)14:3(270)

Baušys, R.; Pankrašovaite, I. 2005. Optimization of architectural layout by the improved genetic algorithm, Journal of Civil Engineering and Management 11(1): 13-21.

Baykasoglu, A.; Gullub, H.; Canakcı, H.; Ozbakır, L. 2008. Prediction of compressive and tensile strength of limestone via genetic programming, Expert Systems with Applications $35(1-2)$ : 111-123.

http://dx.doi.org/10.1016/j.eswa.2007.06.006
Bazant, Z. P.; Krizek, R. J. 1976. Endochronic constitutive law for liquefaction of sand, Journal of the Engineering Mechanics Division ASCE 102(2): 225-238.

Brameier, M.; Banzhaf, W. 2001. A comparison of linear genetic programming and neural networks in medical data mining, IEEE Transactions on Evolutionary Computation 5(1): 17-26. http://dx.doi.org/10.1109/4235.910462

Brameier, M.; Banzhaf, W. 2007. Linear genetic programming. New York: Springer Science + Business Media. 315 p.

Cabalar, A. F.; Cevik, A. 2009. Modelling damping ratio and shear modulus of sand-mica mixtures using neural networks, Engineering Geology 104(1-2): 31-40. http://dx.doi.org/10.1016/j.enggeo.2008.08.005

Cevik, A.; Cabalar, A. F. 2009. Modelling damping ratio and shear modulus of sand-mica mixtures using genetic programming, Expert Systems with Applications 36(4): 7749-7757. http://dx.doi.org/10.1016/j.eswa.2008.09.010

Chen, W. F.; Saleeb, A. F. 1994. Constitutive equations for engineering materials, vol. 1: Plasticity and modeling. New York: Elsevier.

Conrads, M.; Dolezal, O.; Francone, F. D.; Nordin, P. 2004. Discipulus - fast genetic programming based on AIM learning technology. Register Machine Learning Technologies Inc, Littleton, CO.

Dikmen, S. U.; Sonmez, M. 2011. An artificial neural networks model for the estimation of formwork labour, Journal of Civil Engineering and Management 17(3): 340-347. http://dx.doi.org/10.3846/13923730.2011.594154

Francone, F. D.; Deschaine, L. M. 2004. Extending the boundaries of design optimization by integrating fast optimization techniques with machine-code-based, linear genetic programming, Information Sciences 161(3-4): 99-120. http://dx.doi.org/10.1016/j.ins.2003.05.006

Gandomi, A. H.; Alavi, A. H. 2011. Multi-stage genetic programming: a new strategy to nonlinear system modeling, Information Sciences 181(23): 5227-5239. http://dx.doi.org/10.1016/j.ins.2011.07.026

Gandomi, A. H.; Alavi, A. H.; Sahab, M. G. 2010. New formulation for compressive strength of CFRP confined concrete cylinders using linear genetic programming, $\mathrm{Ma}$ terials and Structures 43(7): 963-983. http://dx.doi.org/10.1617/s11527-009-9559-y

Gandomi, A. H.; Alavi, A. H.; Yun, G. J. 2011. Nonlinear modeling of shear strength of SFRCB beams using linear genetic programming, Structural Engineering and $\mathrm{Me}$ chanics 38(1): 1-25. http://dx.doi.org/10.12989/sem.2011.38.1.001

Goldberg, D. 1989. Genetic algorithms in search, optimization and machine learning. Addison-Wesley Longman Publishing Co., Inc. 412 p.

Hoła, J.; Schabowicz, K. 2005. Application of artificial neural networks to determine concrete compressive strength based on non-destructive tests, Journal of Civil Engineering and Management 11(1): 23-32.

Ishihara, K. 1996. Soil behaviour in earthquake geotechnics. Oxford: Clarendon Press. 350 p.

Jennings, P. C. 1964. Periodic response of a general yielding structure, Journal of the Engineering Mechanics Division ASCE 90(EM2): 131-166.

Johari, A.; Habibagahi, G.; Ghahramani, A. 2006. Prediction of soil-water characteristic curve using genetic programming, Journal of Geotechnical and Geoenvironmental Engineering ASCE 132(5): 661-665.

http://dx.doi.org/10.1061/(ASCE)1090-0241(2006)132:5(661)

Kapliński, O.; Janusz, L. 2006. Three phases of multifactor modelling of construction processes, Journal of Civil Engineering and Management 12(2): 127-134. 
Kondner, R. L. 1963. Hyperbolic stress-strain response: cohesive soils, Journal of the Soil Mechanics and Foundations Division ASCE 89(SM1): 115-143.

Koza, J. 1992. Genetic programming, on the programming of computers by means of natural selection. Cambridge: MIT Press. 819 p.

Kramer, S. L. 1996. Geotechnical earthquake engineering. Upper Saddle River: Prentice-Hall. 672 p.

Kulhawy, F. H.; Duncan, J. M. 1972. Stresses and movements of Oroville dam, Journal of the Soil Mechanics and Foundations Division ASCE 98(SM7): 653-665.

Kuo, Y. L.; Jaksa, M. B.; Lyamin, A. V.; Kaggwa, W. S. 2009. ANN-based model for predicting the bearing capacity of strip footing on multi-layered cohesive soil, Computers and Geotechnics 36(3): 503-516.

http://dx.doi.org/10.1016/j.compgeo.2008.07.002

Malinowski, P.; Polarczyk, I.; Piotrowski, J. 2006. Neural model of residential building air infiltration process, Journal of Civil Engineering and Management 12(1): 83-88.

Mitchell, T. 1997. Does machine learning really work?, AI Magazine 18(3): 11-20.

Okura, D. V.; Ansal, A. 2007. Stiffness degradation of natural fine grained soils during cyclic loading, Soil Dynamics and Earthquake Engineering 27(9): 843-854. http://dx.doi.org/10.1016/j.soildyn.2007.01.005

Oltean, M.; Grosan, C. 2003. A comparison of several linear genetic programming techniques, Complex Systems 14(4): 1-29.

Poli, R.; Langdon, W. B.; McPhee, N. F.; Koza, J. R. 2007. Genetic programming: an introductory tutorial and a survey of techniques and applications. Technical report [CES475], University of Essex.

Pradhan, T. B. S. 1989. The behavior of sand subjected to monotonic and cyclic loadings. PhD thesis. Kyoto University, Japan.

Pyke, R. M. 1979. Nonlinear soil models for irregular cyclic loadings, Journal of Geotechnical Engineering ASCE 105(6): 715-726.

Refaeilzadeh, P.; Tang, L.; Liu, H. 2009. Cross validation, in Özsu, M. T.; Liu, L. (Eds.). Encyclopedia of database systems. Springer, 532-538.

Sagaseta, C.; Cuellar, V.; Pastor, M. 1991. Cyclic loading, in Proceedings of $10^{\text {th }}$ ECSMFE, 23-30 May 1991, Florence, 981-999.
Schabowicz, K.; Hola, B. 2007. Mathematical-neural model for assessing productivity of earthmoving machinery, Journal of Civil Engineering and Management 13(1): 47-54

Šešok, D.; Belevicius, R. 2008. Global optimization of trusses with a modified genetic algorithm, Journal of Civil Engineering and Management 14(3): 147-154. http://dx.doi.org/10.3846/1392-3730.2008.14.10

Šešok, D.; Mockus, J.; Belevicius, R.; Kačeniauskas, A. 2010. Global optimization of grillages using simulated annealing and high performance computing, Journal of Civil Engineering and Management 16(1): 95-101. http://dx.doi.org/10.3846/jcem.2010.09

Shahnazari, H.; Dehnavi, Y.; Alavi, A. H. 2010. Numerical modeling of stress-strain behavior of sand under cyclic loading, Engineering Geology 116(1-2): 53-72. http://dx.doi.org/10.1016/j.enggeo.2010.07.007

Shahnazari, H.; Towhata, I. 2002. Torsion shear tests on cyclic stress-dilatancy relationship of sand, Soils and Foundations 42(1): 105-109. http://dx.doi.org/10.3208/sandf.42.105

Sonmez, R.; Ontepeli, B. 2009. Predesign cost estimation of urban railway projects with parametric modeling, Journal of Civil Engineering and Management 15(4): 405-409. http://dx.doi.org/10.3846/1392-3730.2009.15.405-409

Sun, K. T.; Lin, Y. C.; Wua, C. Y.; Huang, Y. M. 2009. An application of the genetic programming technique to strategy development, Expert Systems with Applications 36(3): 5157-5161. http://dx.doi.org/10.1016/j.eswa.2008.06.066

Tatsuoka, F.; Masuda, T.; Siddiquee, M. S. A.; Koseki, J. 2003. Modeling the stress-strain relations of sand in cyclic plane strain loading, Journal of Geotechnical and Geoenvironmental Engineering ASCE 129(6): 450-467.

Thiers, G. R.; Seed, H. B. 1968. Cyclic stress-strain characteristics of clay, Journal of Soil Mechanics and Foundation Engineering Division ASCE 94(2): 555-69.

Weise, T. 2009. Global optimization algorithms - theory and application. Germany (self-published) [online], [cited 20 August 2012]. Available from Internet: http://www.it-weise.de

Zhang, J.; Andrus, R. D.; Juang, C. H. 2005. Normalized shear modulus and material damping ratio relationships, Journal of Geotechnical and Geoenvironmental Engineering ASCE 131(4): 453-464.

http://dx.doi.org/10.1061/(ASCE)1090-0241(2005)131:4(453)

Habib SHAHNAZARI. Received his BSc in Civil Engineering from Sharif University of Technology and MSc degree in Geotechnical Engineering from University of Tehran, Iran. He received his PhD degree from the University of Tokyo, Japan in Geotechnical Engineering. He is currently an Assistant Professor in School of Civil Engineering at Iran University of Science and Technology (IUST), Tehran, Iran. He has published over 80 papers in international journals, international and national conferences. His research interests include earthquake geotechnical engineering, shaking table and centrifuge model tests, underground structures, dynamic stress-strain behaviour of reinforced and unreinforced sands, and applications of soft computing techniques in engineering.

Yasser DEHNAVI. Received his BSc in Hormozgan University and MSc degree in Geotechnical Engineering from Iran University of Science and Technology (IUST), Tehran, Iran. He received his PhD degree from IUST in Geotechnical and Geoenvironmental Engineering. He is currently an Assistant Professor in Department of Civil Engineering at University of Bojnord, Bojnord, Iran. He has published over 20 papers in international journals, national conferences. His research interests include earthquake geotechnical engineering, evaluation of dynamic behaviour of calcareous sands, dynamic stress-strain behaviour of reinforced and unreinforced sands, and applications of soft computing techniques in geotechnical engineering.

Amir H. ALAVI. Graduated in Civil and Geotechnical Engineering from Iran University of Science \& Technology (IUST), Tehran, Iran. He used to be a lecturer in Eqbal Lahoori Institute of Higher Education and serve as a researcher in School of Civil Engineering at IUST. He is currently a researcher at the Department of Civil \& Environmental Engineering at Michigan State University (MSU), MI, USA. He has over 100 publications in book chapters, indexed journals, and conference proceedings. He has registered two patents and published two books in Elsevier. He is on the editorial board of several journals and serves as a regular reviewer for a number of indexed journals (Elsevier, Springer, Wiley, Taylor \& Francis, etc.). As of October 2013, he has been selected among the Scholar Google 400 Most Cited Authors in Civil Engineering. His current research at MSU is focused on Structural Health Monitoring of Pavement Systems Using Self-Powered Strain Sensors. His research interests include analysis and design using metaheuristic, statistical and probabilistic methods, pavement materials and pavement design, geotechnical engineering, and composite materials. 